\title{
Research of Regional Sports Resources Perspective of Martial Arts and the National Traditional Sports Professional Curriculum Resources
}

\author{
Weihua Yao \\ College of Physical Education, Luoyang Normal University, Luoyang, Henan 471000
}

\begin{abstract}
Keywords: Martial arts and traditional national sports major, Regional sports resources, Curriculum resources, Develop
\end{abstract}

\begin{abstract}
From the Angle of regional sports resources, martial arts and traditional national sports major courses in colleges and universities resources present situation and the problems were analyzed, and put forward by using local characteristics, rich inheritance and utilization of curriculum resources, create the "school-based" characteristic course, promote the traditional martial arts in university and national professional sports and regional sports resources fusion and draw lessons from each other.
\end{abstract}

\section{Introduction}

In order to promote the healthy development of national traditional sports professional, in 2012 the ministry of education in the new round of adjustment of professional catalogue, will change for the traditional national sports major for martial arts and the national traditional sports professional, to highlight the main status of $\mathrm{Wu} \mathrm{Shu}$ and priority, it is more reasonable to develop the national traditional sports professional norms. As the opening of a national traditional sports professional colleges, should take an important period of development for the traditional national sports major in the process of protecting and inheriting traditional culture, make full use of regional sports resources, pay attention to the traditional martial arts of good theory and technology, the characteristic of national traditional sports for development and utilization of resources, gradually improve and establish a martial arts and traditional sports curriculum resources management system, school-based curriculum development characteristics, development characteristics of sports. This to promote martial arts and the development of traditional national sports major competitive advantage, and prompt the healthy development of the professional has the extremely important significance.

\section{The meaning of "school-based" regional sports resources development}

Resources refers to the various factors and conditions of human society, not only including natural resources, it should also include human labor elements such as society, economy, technology and manpower and material resources, financial resources, information, knowledge and other resources. [1] regional sports resources is refers to a specific area of a certain cohesion and significant effect to the regional development of sports resources. In practice, it is people's sports resources for the development of undertakings of physical culture and sports have to rely on. Physical space-time determines that the overall effect of regional sports resources will eventually impact and response to various sports management activities, sports economic activities, social activities, sports teaching and training, and other sports activities, such as the realistic effect. Therefore, fully understanding the distribution characteristics of regional sports resources and advantages, and to carry on the reasonable development and utilization, will have a positive impact on the development of regional sports.

Regional curriculum resources including in students' families, communities, and even the entire social sports resources can be used in the sports teaching activities. The preservation and display sports civilization achievements of public facilities, such as gymnasium, library, museum is also important curriculum resources; Affect the production and living of human society values, religious ethics and customs has direct relationship with sports curriculum activities, also is the indispensable social sports curriculum resources. Student family sports equipment, equipment, sports books, network and so on also sports curriculum resources cannot be ignored. 
Refers to the development of sports school-based curriculum of school physical education teachers as the main body, the sports and health course standard "in the country and the local" sports and health curriculum implementation plan "under the guidance of, on the basis of the nature of the school itself, characteristics, conditions, and can make use of and development of sports resources, to meet the demand of the students' sports and promote students' health and to carry out a series of activities process. [2]"school-based" regional sports resources development, namely the regional sports resources as a physical education school resources for development. University departments can give full play to the management and guidance functions, composition between the school and the school, school and community, the association between sports bureau and the department of education, investigating all kinds of sports resources in the area, analysis, integration, set up regional operational platform for the development of sports resources "school-based", the maximum solve teachers, sites, equipment, facilities the actual problems of insufficient, form of resource sharing, mutual cooperation in the area of the new situation.

\section{The problems existing in the curriculum resource utilization between martial arts and traditional national sports major}

\section{The lack of national traditional sports culture heritage}

In the higher sports colleges' traditional teaching process, teachers emphasize the action skills of older, ignore the teaching of national traditional sports culture, the cultivation of student's Wu Shu etiquette also limited in fist-palm salute, form education, lack of effective way to implement the specific content of the etiquette education. Laying emphasis on the motor skills older, can make the students master the basic skills, is easy to make the person produces psychological, that was supposed to enjoy the learning process become the passive to accept, is not conducive to student's understanding of national spirit and traditional culture, more can't realize the real meaning of national traditional sports. Especially in martial arts teaching, the excessive pursuit of its physical properties, to some extent, ignored the traditional martial arts culture education value, cause the school martial arts to promote the connotation of the traditional culture and education in the process of missing, amid a shrinking number of college $\mathrm{Wu}$ Shu practice, its development." Martial arts teaching what we have seen lose the things we did not find. What may be a corner in the above the water of the sea ice, loss of water below the body of the iceberg." [3] National traditional sports is a comprehensive discipline, and the humanities mutual infiltration of cultural development and the spread of world cultural achievements, can develop the student's field of vision, enhance students' ability of cross-cultural communication, and martial arts and the national traditional sports professional teaching in traditional culture teaching content obviously at a disadvantage.

\section{Singleness course resources, lack of local characteristics}

At present in colleges and universities to open national traditional sports professional training scheme design, mostly follow professional sports colleges and universities or the original martial arts professional training mode, position is not clear, single curriculum resources, humanities teaching content, course system setting is not enough scientific. Schools can according to the regional characteristics, as far as possible the introduction of excellent cultural achievements and national folk traditional sports project to enrich the teaching content, enhance students' ability of cross-cultural communication, make up for the lack of curriculum resources.

\section{Not very reasonable curriculum resources configuration}

The allocation of resources refers to through the different allocation of sports resources, keep the corresponding proportion in the process of production, the process of maximum meet the needs of the development of competitive sports. [4] Curriculum resources configuration purpose is to make the limited resources by reasonable arrangement and combination to maximize the benefit of pursuit. Curriculum resource Settings for the traditional national sports major stress imparting professional skills and knowledge, and to applied courses and practical teaching link. As graduates increased year by year, and the limitation of social conditions, single graduates skill, professional adaptability is poorer, practical ability and the ability to analyze and solve problems independently, the employment 
situation is not optimistic, partly reflects the talent training and the problems of the curriculum, it must draw high attention.

\section{The countermeasures of martial arts and the national traditional sports professional sports curriculum resources utilization}

\section{Correct understanding of advantage, form brand regional culture resources}

National traditional sports culture resources include not only the mainstream culture of the Chinese nation's traditional sports, but also including the non-mainstream ethnic minority sports activities, these are all in the specific geographical environment, conditions and cultural background along with the development of the modern life. It can be on the carrier of certain material entities can also be something purely human spiritual culture. Carrier of tangible and intangible cultural content depends on each other mutual infiltration has obvious modernity, nationality and artistic quality. [5] more and more foreigners like traditional Chinese sports is the real reason they want to by a form of body movement feeling its cultural value, social value and the western society reflected in the process of different historical and cultural environment.

Sports colleges' martial arts and traditional sports specialty is the position of the promotion and development of traditional sports, it can not only inherit and development of traditional sports to provide a platform, but also can be the concrete practice of the ethnic traditional culture inheriting carrier. Through to the traditional cultural resources development, to include it in the martial arts and the national traditional sports professional student's field of vision and scope, maximizing mutual fusion and reference to professional courses and cultural education, make sports professional course and the traditional culture penetrating into naturally integrated into the teaching process, subtly causes the student to absorb the essence of traditional culture, to enhance the students' humanistic quality and national emotion, thus better inheriting the excellent traditional culture.

\section{Use bundled development integration of regional sports resources, to rich school curriculum resources}

Curriculum system is the main carrier of teaching contents; it directly decides the education object, smart structure, and the overall quality of knowledge structure, related to the implementation of training objectives. According to professional training target, the future of the traditional national sports major should cultivate good scientific literacy skills, the method and theory, traditional ethnic sports knowledge and skills, to adapt to the social development of the specialized personnel of having both ability and political integrity. To be guided by market needs, in order to "optimize the curriculum system and updating the teaching contents, adjust the structure of knowledge, improve the practical ability" as the guiding ideology, to actively optimize training scheme, necessary adjustment of curriculum structure.

For school-based curriculum development is under the guidance of national curriculum and local curriculum of school-based curriculum development, is the national curriculum and local curriculum of beneficial supplement. Excellent traditional $\mathrm{Wu}$ Shu be separated and various forms of national traditional sports, recreational, interesting, and with local materials, the request is not high economic value, the site and have fun sex is strong, the characteristics of high fitness value. These excellent national sports activities should be included in the national traditional sports curriculum construction, speed up the development of traditional sports keeping in good health and folk sports two professional directions, rich curriculum resources system.

The rational allocation of curriculum resources, promoting the comprehensive ability of students

The optimization of curriculum resources, and integration, the complementary advantages of resources, reduce the resource consumed, maximum limit to promoting the comprehensive practical ability of students. [4]Practice ability is the standard for testing subject construction, strengthen the training of students' practical ability, increase practice curriculum configuration, pay attention to the theory with practice, gradually improve the students' knowledge structure, make them in the mastery of professional theory and technical basis, improve the practice ability, enrich their knowledge reserves, to the society to lay a good foundation for the future. By strengthening teaching, training 
and academic, scientific research, highlight the core characteristics of undergraduate education, desalination compulsory courses, establish an elective system, increase practice credits, construction with the ideological and political character and humanistic quality training courses, professional courses, scientific research and innovation thinking courses and elective course for the contents of the five most, with the integration of theory and practice of curriculum system. According to the professional characteristics of martial arts and traditional sports, realize applied talents training target of one body with two wings, meet the needs of the society and the development of national traditional sports itself.

\section{Make full use of geographical advantages, to form the school characteristic project}

Martial arts and traditional national sports major should make full use of regional cultural advantage, in addition to the complete teaching contents stipulated by the state, should also show the features of regional culture characteristics of professional courses, such as some of the traditional national sports major in Henan colleges and universities runs of Chen style Tai Jiquan, shaolin, the song tong back fist, Xin yi liu he boxing, etc. Traditional sports keeping in good health course, guided by the representative should be taught YangShengGong, martial arts fitness method, Wuqinxi, Ba duanjin, Yi jin jing, six travelling and so on the content of the health qigong; Folk sports in addition to the opening of China's national traditional sports, such as wrestling, dragon dance lion dance, dragon boat, yangko, gyro, rope skipping, shuttlecock and so on, should also be the opening of a foreign national sports, such as boxing, judo and taekwondo, forming a set of reasonable perfect characteristic for the traditional national sports major curriculum system, make it a regular feature of professional colleges and universities have a certain advantage.

In addition, rank in Chinese martial arts is the state general administration of sports $\mathrm{Wu}$ Shu sports management center and the Chinese $\mathrm{Wu}$ Shu association, rouse national spirit, inherit the national culture, improve the people's physical fitness, promote the development of Wu Shu sports, improve the level of martial arts techniques and theory, establish a standardized system of the national Wu Shu exercise and standards, a comprehensive evaluation for practitioners of Wu Shu grade level, specially formulated a martial arts class system. Rank in the implementation of the can arouse the enthusiasm of practitioners, the maximum number of expanding $\mathrm{Wu}$ Shu practitioner, mining, sorting, inherit and develop folk traditional martial arts techniques and theory essence, for promoting the popularization and development of martial arts fitness movement is of great significance. Martial arts sport management center of the state sport general administration rank in primary and middle schools at all levels are required to offer martial arts curriculum, as the main force of cultivate martial arts teaching in colleges and universities, should be popularized as an opportunity to rank in martial arts, use of geographical advantages, highlight the characteristics of their own, will rank in the Chinese Wu Shu series is introduced into the teaching content. With single practiced and prepared as the main characteristics of the combination of rank in martial arts, its novel approach to learning and section of the model, not only enriches the martial arts and the national traditional sports professional curriculum resources, but also can stimulate students interest in learning, conducive to the development of students' comprehensive ability, martial arts teaching bring new vitality for colleges and universities.

\section{Conclusion}

Martial arts and the national traditional sports professional development face many opportunities and challenges, from the perspective of regional sports resources, from the use of curriculum resources, maximizing regional sports resources and traditional sports in universities with reference to the professional development of organic fusion, gradually improve and establish a martial arts and traditional sports curriculum resources management system, create martial arts with the "school-based" characteristic for the traditional national sports major courses, making it a national traditional culture heritage practice carrier, to the health of $\mathrm{Wu}$ Shu and the traditional national sports major development has the vital significance. 


\section{Acknowledgments}

This paper is the research project for department of soft science in 2011 in Henan province (number: 112400450509).

\section{References}

[1] Xie Ying. Research - the regional sports resources and the development of the western theory of sports resources. Shanghai sports institute, ,2003:25-27

[2] Liu Yi, Cai Zhonglin. The educational experience and professional development path of martial arts with national and traditional sports. Journal of Shanghai sports institute,2011:9:73-76

[3] Gao Chulan.. The research of national traditional sports professional curriculum and teaching contents. Journal of Shanghai sports institute,2005,29 (5) :102-105.

[4] Song Wenxian. Local normal colleges training mode innovation and practice -- in luoyang normal college, for example. Journal of Henan education,2009.

[5] Yao Weihua. Look at regional sports resources in colleges and universities in the development of national traditional sports professional role. Journal of martial arts science,2011,8:94

[6] Tao Ping. College national traditional sports professional course curriculum research. Northeast normal university,2006:7 